Article

\title{
Bromocresol Green/Mesoporous Silica Adsorbent for Ammonia Gas Sensing via an Optical Sensing Instrument
}

\author{
Yu-Chang Chang ${ }^{1}$, Hsunling Bai ${ }^{1, *}$, Shou-Nan $\mathrm{Li}^{2}$ and Chun-Nan Kuo ${ }^{2}$ \\ 1 Institute of Environmental Engineering, National Chiao Tung University, Hsinchu 30010, Taiwan; \\ E-Mail: bruce0313@gmail.com
}

2 Green Energy and Environment Research Laboratories, Industrial Technology Research Institute, Hsinchu 31040, Taiwan; E-Mails: SNLi@itri.org.tw (S.-N.L.); chunnankuo@itri.org.tw (C.-N.K.)

* Author to whom correspondence should be addressed; E-Mail: hlbai@ mail.nctu.edu.tw;

Tel: +886-3-573-1868; Fax: +886-3-572-5958.

Received: 20 January 2011; in revised form: 18 March 2011 / Accepted: 18 March 2011 /

Published: 6 April 2011

\begin{abstract}
A meso-structured Al-MCM-41 material was impregnated with bromocresol green (BG) dye and then incorporated into a UV-Vis DRA spectroscopic instrument for the online detection of ammonia gas. The absorption response of the Al-MCM-41/BG ammonia sensing material was very sensitive at the optical absorption wavelength of $630 \mathrm{~nm}$. A high linear correlation was achieved for ppmv and sub-ppmv levels of ammonia gas. The response time for the quantitative detection of ammonia gas concentrations ranging from 0.25 to $2.0 \mathrm{ppmv}$ was only a few minutes. The lower detection limit achieved was 0.185 ppmv. The color change process was fully reversible during tens of cycling tests. These features together make this mesoporous Al-MCM-41 material very promising for optical sensing applications.
\end{abstract}

Keywords: ammonia gas; optical sensor; mesoporous silica material; UV-Vis absorbance; bromocresol green dye

\section{Introduction}

Sensing low concentrations of chemical vapors is an area of great interest with many practical applications. In semiconductor and optoelectronic manufacturing, a small amount of ammonia gas can lead to serious damage to electronic devices and decrease product yields [1]. Thus, in these industries 
ammonia gas detection at sub-ppmv levels is required for ensuring product quality. For environmental purposes, ammonia can be smelled at a level higher than 0.04 57 ppmv [2]. It irritates eyes, throats and noses and affects human health when it reaches the 50-100 ppmv level [3]. In order to avoid hazards, the US Occupational Safety and Health Administration (OSHA) limits worker ammonia exposure to 50 ppmv over a $8 \mathrm{~h}$ work day and $40 \mathrm{~h}$ per week [4], while the US National Institute of Occupational Safety and Health (NIOSH) proposes that the ammonia concentration should not exceed 25 ppmv over $10 \mathrm{~h}$ per day or $40 \mathrm{~h}$ per week in the workplace [5].

Several different techniques have been developed for sensing ammonia gas. Conventional real-time gas monitoring has commonly been performed employing electrochemical sensors [6]. However, such techniques have inherent disadvantages such as the need for reference electrodes and the development of surface potentials, etc. Moreover, they can't monitor low ammonia concentrations because of the high bias. Many of these problems can be solved by employing optical sensors using chemical sensing materials. Optical sensors have attracted much attention because of their accuracy and high sensitivity to low ammonia gas concentrations. Besides, the detection can be achieved without any direct contact between the expensive optical parts and the corrosive ammonia gas samples [7]. Such features may lead to wide acceptance in real applications, and provide a solution for detecting ammonia at sub-ppmv levels.

Many different materials have been employed to entrap the dyes used for ammonia detection. For instance, Markovics et al. [8] used bromocresol green indicators immobilized on an anodized aluminum substrate, and found that they could measure 10-90 ppmv ammonia gas in a few seconds. Although this material had the advantage of a fast response time, its lower detection limit was still too high for practical use. Courbat et al. [9] proposed another material, bromophenol blue-doped poly(methyl methacrylate), which could be used to detect ammonia in sub-ppmv levels. However, the quantitation time in their study was over $30 \mathrm{~min}$. An ideal sensing material for optical sensors should offer some advantages such as a fast response (i.e., less than $10 \mathrm{~min}$ ), high sensitivity, and be inexpensive in order to achieve widespread routine use. Thus, new materials are required to meet these needs.

More recently, ordered mesoporous silica materials have become of interest as chemical sensing materials due to their uniform porosity, mechanical stiffness, thermal stability, high surface areas and pore volumes, tunable pore sizes and the possibility of incorporation of hetero-atoms into the silica structure [10-12]. Fiorilli et al. [13] and Onida et al. [14] used Reichardt's dye impregnated on mesoporous SBA-15 to develop ammonia sensing materials. Tao et al. [15] used an organic dye-impregnated porous silica material to detect 1-5 ppmv ammonia gas in 20 min. Nevertheless, to the authors' knowledge, no literature has discussed employing ordered mesoporous silica materials as chemical sensing materials for the quantification of ammonia gas at sub-ppmv levels.

The purpose of this study was to develop a mesoporous silica material which could measure ammonia gas concentrations at sub-ppmv levels. In this work, a highly sensitive and fully reversible ammonia sensing material is proposed using bromocresol green, an organic dye, impregnated on mesoporous Al-MCM-41(50). Since the color of the dye-impregnated Al-MCM-41(50) will change during ammonia adsorption, it can be incorporated into a UV-Vis Diffuse Reflection Accessory (DRA) spectroscopic instrument for the online detection of ammonia gas. The color change process was 
repeated for tens of cycles to check for the reversibility of the sensing material on the ammonia gas detection.

\section{Experimental}

\subsection{Preparation of Mesoporous Al-MCM-41}

Mesoporous Al-MCM-41(nSi/nAl = 50) molecular sieves were synthesized by a hydrothermal treatment method based on our prior experience [16]. Cetyltrimethylammonium bromide (CTAB, $\mathrm{C}_{19} \mathrm{H}_{42} \mathrm{BrN}$ ) was employed as the structure-directing template in the synthesis. The molar composition of the gel mixture was $1 \mathrm{Na}_{2} \mathrm{SiO}_{3}: 0.005 \mathrm{Al}_{2} \mathrm{O}_{3}: 0.11 \mathrm{C}_{19} \mathrm{H}_{42} \mathrm{BrN}: 0.35 \mathrm{H}_{2} \mathrm{SO}_{4}: 40.3 \mathrm{H}_{2} \mathrm{O}$. In a typical synthesis procedure, $21.2 \mathrm{~g}$ of sodium metasilicate (Kanto Chemical Co. Inc., Japan) was dissolved in $80 \mathrm{~mL}$ de-ionized (DI) water and then combined with aluminum sulfate $(0.342 \mathrm{~g}$ dissolved in $20 \mathrm{~mL}$ of DI water). The resulting mixture was stirred vigorously for $30 \mathrm{~min}$. Then, approximately $11.1 \mathrm{~mL}$ $\mathrm{H}_{2} \mathrm{SO}_{4}$ (Panreac Chemicals Co., Spain) in $100 \mathrm{~mL}$ of DI water was added to the above mixture with constant stirring to bring down the $\mathrm{pH}$ to 10.5 and form a gel. After stirring, $7.2 \mathrm{~g}$ of CTAB (dissolved in $25 \mathrm{~mL}$ of DI water) was added slowly into the above mixture and the combined mixture was stirred for three additional hours. The resulting gel mixture was transferred into a Teflon coated autoclave and kept in an oven at $145{ }^{\circ} \mathrm{C}$ for $36 \mathrm{~h}$. After cooling to the room temperature, the resultant solid was recovered by filtration, washed with DI water and dried in an oven at $100{ }^{\circ} \mathrm{C}$ for $6 \mathrm{~h}$. Finally, the organic template was removed by using a muffle furnace in air at $550{ }^{\circ} \mathrm{C}$ for $10 \mathrm{~h}$.

\subsection{Impregnation of Bromocresol Green Indicator}

The dye bromocresol green (BG, 2,6-dibromo-4-[7-(3,5-dibromo-4-hydroxy-2-methylphenyl)-9,9dioxo-8-oxa-9 $\lambda$ 6-thiabicyclo[4.3.0]nona-1,3,5-trien-7-yl]-3-methylphenol) is a weak organic acid whose absorbance spectrum is quite different from that of its conjugate base. The color of BG solution changes from yellow to blue over the $\mathrm{pH}$ range of 3.8-5.4 [17]. The Al-MCM-41(50)/BG impregnation process was evaluated under different ratios of BG to Al-MCM-41(50) as well as different process times and temperatures. The optimal dye impregnating procedure is as follows: $0.001 \mathrm{~g}$ of BG powder (Acros Organics Co., USA) and $100 \mathrm{~mL}$ of acetone (Merck \& Co. Inc., Germany) were mixed and stirred for $10 \mathrm{~min}$. Then $0.1 \mathrm{~g}$ of Al-MCM-41(50) powder was added into the mixture solution and stirred for $3 \mathrm{~h}$. The resulting yellow solution was transferred into an evaporating dish and kept in an oven at $110{ }^{\circ} \mathrm{C}$ for 3-6 h. Finally, the orange colored sample of BG dye impregnated-Al-MCM-41(50) material was collected and named as Al-MCM-41(50)/BG hereafter.

\subsection{Material Characterization}

The powder X-ray diffraction patterns of Al-MCM-41 (50) and dye impregnated samples were recorded using a Panalytical X'Pert Pro MRD powder diffractometer, where a $\mathrm{Cu}$ target Ka-ray (operating at $30 \mathrm{kV}$ and $20 \mathrm{~mA}$ ) was used as the X-ray source. The scanning range was $2 \theta=2^{\circ}-10^{\circ}$ with 400 data points and the scanning speed was $2 \%$ min. The d-spacing $\left(\mathrm{d}_{\mathrm{hkl}}\right)$ of material was calculated by the Bragg diffraction equation. 
The Brunauer-Emmett-Teller (BET) specific surface area, specific pore volume and BJH average pore diameter of the materials were measured by $\mathrm{N}_{2}$ adsorption-desorption isotherms at $77 \mathrm{~K}$ using a surface area analyzer (Micromeritics, ASAP 2020). All the materials were degassed for $6 \mathrm{~h}$ at $120{ }^{\circ} \mathrm{C}$ under vacuum ( $10^{-6}$ mbar) prior to the $\mathrm{N}_{2}$ adsorption-desorption experiments.

Transmission electron microscopy (JEOL JEM 1210, Japan) was carried out on a JEOL JEM-2010 microscope at $120 \mathrm{keV}$. The samples (5-10 mg) were ultrasonicated in ethanol and dispersed on carbon film supported on copper grids (200 mesh).

\subsection{Online Ammonia Gas Detection}

The experimental set-up for the in situ measurements in order to test the quantitation ability of the sensing material in sub-ppmv ammonia gas is shown schematically in Figure 1. The UV-Vis spectrometer (EVOLUTION 300, Thermo Scientific, England) combined with a Diffuse Reflection Accessory (DRA, the Praying Mantis ${ }^{\mathrm{TM}}$ DRP-NI9 and HVC-VUV-4, Harrick Scientific, Pleasantville, NY, USA) monitored the optical properties of solid samples for online examination purpose and the data were recorded by a computer. The scan frequency was once per minute over the wavelength range from 400 to $850 \mathrm{~nm}$.

Both $\mathrm{NH}_{3}$ and $\mathrm{N}_{2}$ gases were obtained from gas cylinders. The $\mathrm{NH}_{3}$ concentration was quantified by a Fourier Transform Infrared (FTIR) spectrometer (Work IR-104, ABB Bomem, QC, Canada) before each test. Then the $\mathrm{NH}_{3}$ and $\mathrm{N}_{2}$ gas streams were mixed in a mixing chamber as shown in Figure 1. All the gas flow rates were controlled by mass flow controllers (MKS, 1179A, USA), and the flow rate was re-checked by a bubble meter before each test. Different $\mathrm{NH}_{3}$ inlet gas concentrations were obtained by adjusting the $\mathrm{N}_{2}$ and $\mathrm{NH}_{3}$ gas flow rates to have a total gas flow rate of $400 \mathrm{~mL} / \mathrm{min}$ for all test conditions. Before each test, the UV-Vis DRA spectroscopic instrument was purged with $\mathrm{N}_{2}$ for 20 min in order to minimize experimental errors. The temperature of this system was at room temperature $\left(24 \pm 1{ }^{\circ} \mathrm{C}\right)$. The relative humidity of the gas flow was monitored to be $6 \pm 1 \%$ by a humidity and temperature meter (Center 310, JDC Electronic SA, Switzerland), which corresponds to an absolute humidity of less than 2,500 ppmv. The sensing material used in this experiment is in pellet form of $6 \mathrm{~mm}$ in diameter. And desorption process was done by heating at $150{ }^{\circ} \mathrm{C}$ for $1 \mathrm{~h}$ to ensure total desorption.

Figure 1. Schematic diagram of a UV-Vis DRA spectroscopic instrument for $\mathrm{NH}_{3}$ sensing.

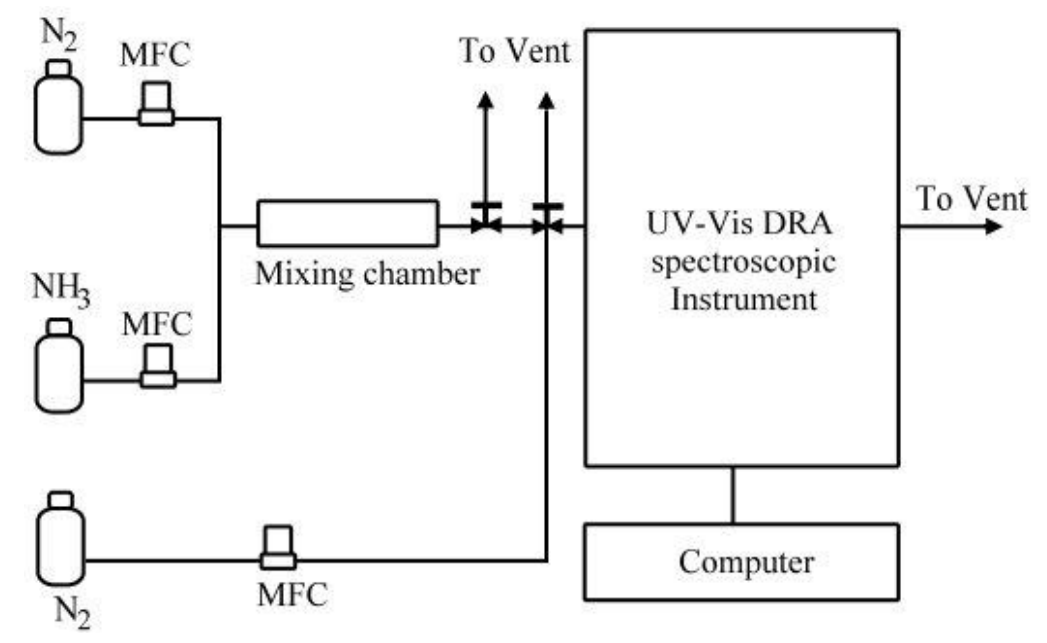




\section{Results and Discussion}

\subsection{Material Characterization}

The XRD patterns of Al-MCM-41(50) and dye impregnated Al-MCM-41(50) are shown in Figure 2. It appears that both Al-MCM-41(50) and Al-MCM-41(50)/BG present a well ordered structure and the peaks are indexed on a hexagonal lattice which corresponded to (100), (110) and (200) [10,18-20]. This indicates that the dye impregnation did not affect the ordered mesoporous structure of Al-MCM-41(50).

Figure 2. Powder X-ray diffraction pattern of Al-MCM-41(50) and dye impregnated Al-MCM-41(50)/BG.

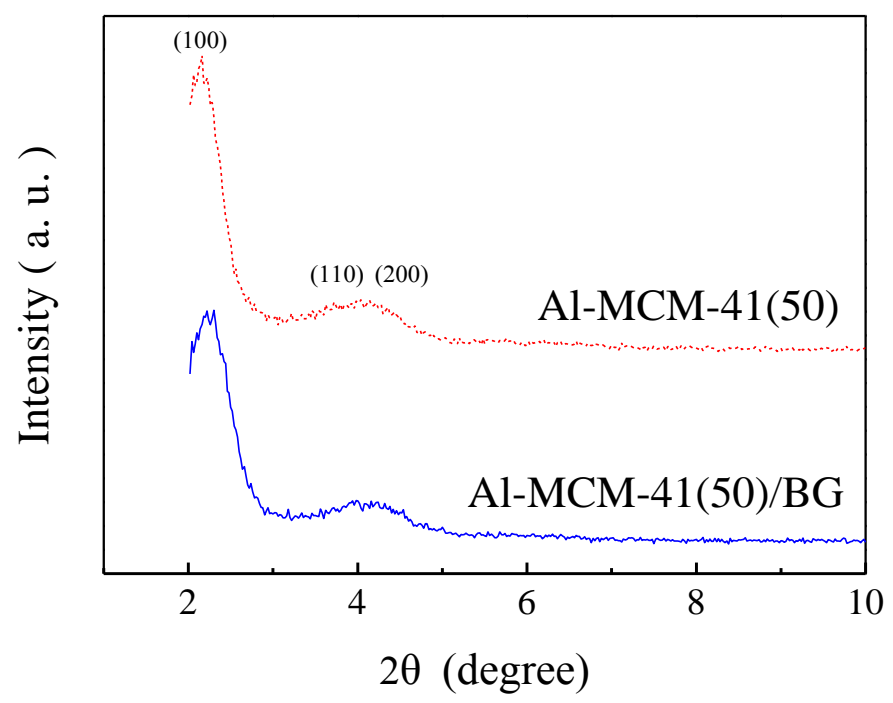

Figure 3 shows the $\mathrm{N}_{2}$ adsorption/desorption isotherms of Al-MCM-41(50) and dye impregnated Al-MCM-41(50)/BG. The isotherms are type IV according to the IUPAC classification and show an uptake of $\mathrm{N}_{2}$ due to capillary condensation in the relative pressure $\left(\mathrm{p} / \mathrm{p}_{0}\right)$ range of $0.3-0.4$. Such isotherms are characteristic of mesoporous materials with a transitional pore size ranging from microporous to mesoporous. The pore size distribution of Al-MCM-41(50) was around $2.7 \mathrm{~nm}$ with the BET surface area of $985 \mathrm{~m}^{2} / \mathrm{g}$.

The TEM images of dye impregnated Al-MCM-41(50) is shown in Figure 4. The hexagonal pore structure of dye impregnated Al-MCM-41(50) was observable in the TEM images. The clear observation of the pores of dye impregnated Al-MCM-41(50) indicates that the dye molecules did not block the nano-pore structure of the host material. 
Figure 3. Nitrogen adsorption-desorption isotherms of dye impregnated Al-MCM-41(50).

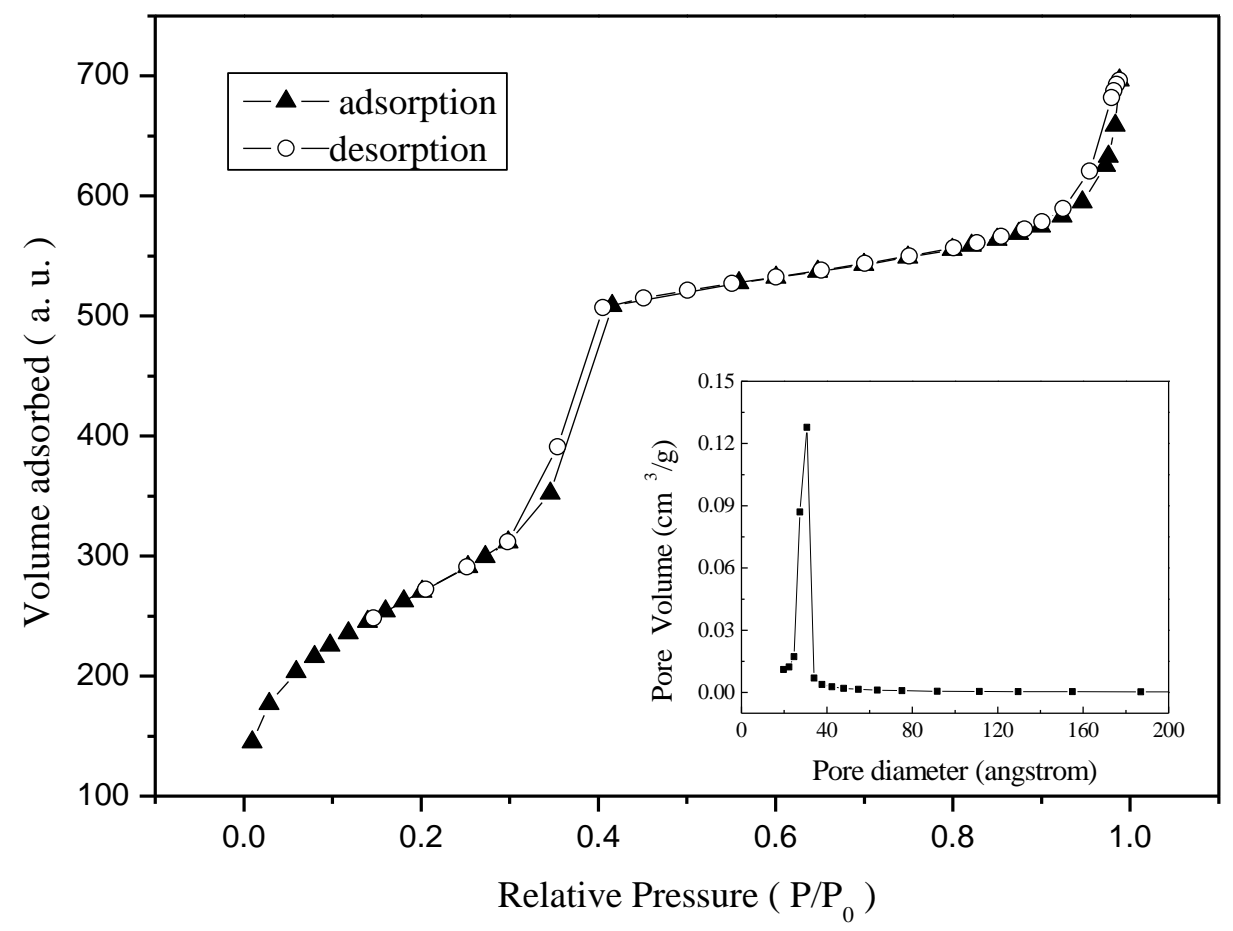

Figure 4. Transmission electron micrographs of dye-impregnated Al-MCM-41(50).

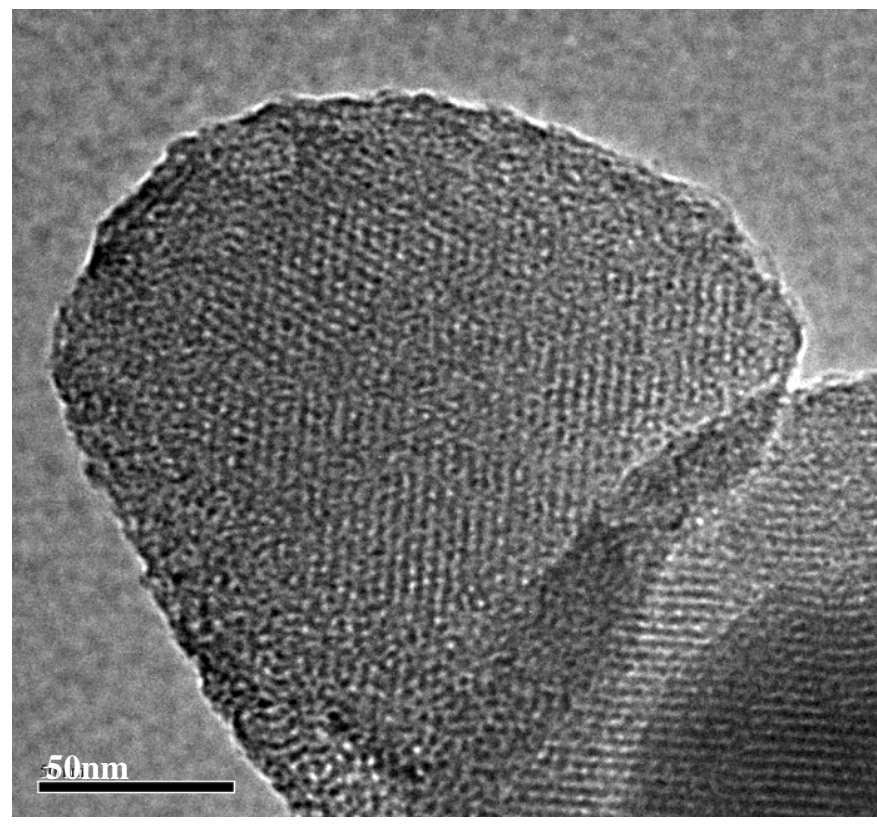

\subsection{Ammonia Gas Sensing}

The sensor is based on the spectral properties of bromocresol green. Bromocresol green (tetrabromo- $m$-cresol sulfonphthalein) is an organic dye which reacts with ammonia to form an ammonium salt. Like most $\mathrm{pH}$ indicators, bromocresol green is a weak organic acid whose absorbance spectrum is quite different from that of its conjugate base [21]. The color of BG solution changes from yellow to blue over the $\mathrm{pH}$ range of 3.8-5.4, which indicates the equilibrium shifts to the de-protonated, arylmethine form of the dye [22]. This organic dye immobilized in the Al-MCM-41(50) 
will change its color to blue when it reacts with ammonia gas. After heating, the color of sensing material will turn back to orange.

Bromocresol green was selected based on the study of Markovics et al. [8], who compared three different dyes: bromophenol blue (BPB), bromocresol green (BG) and bromocresol purple (BCP) for ammonia detection. The respective pKa values are 3.8 for $\mathrm{BPB}, 4.7$ for $\mathrm{BG}$, and 6.0 for $\mathrm{BCP}$. This study showed that the lower the pKa value of the dye, the faster the response time. However, the decrease in the pKa value of the dye also results in a longer desorption time. Thus BG should offer an appropriate compromise between the needs for fast response and fast desorption. The optical properties of the sensing materials were observed through the DRA-UV/Vis spectrometer. When a gas sample containing ammonia molecules was brought into contact with the dye-impregnated Al-MCM-41(50), ammonia molecules in the gas sample diffuse into the porous materials and react with the BG dye. This reaction reduces the concentration of $\mathrm{BG}$ and increases the concentration of $\mathrm{BG}$ salt. Thus, the absorption signal of the BG salt is increased with time upon adsorption of ammonia molecules.

Figure 5 shows the recorded absorption spectra change of the Al-MCM-41(50)/BG with respect to time. The absorbance increased most significantly at around $630 \mathrm{~nm}$ as the ammonia adsorption time increased. This peak belonged to the ammonia absorption peak. At this peak of absorption the color of the Al-MCM-41(50)/BG was blue. Therefore, the difference in the optical absorbance signal at $630 \mathrm{~nm}$ was monitored as the indicating signal. In the following part, the variation in the $630 \mathrm{~nm}$ absorbance from time zero to the test time was calculated and referred as the "absorbance difference".

Figure 5. UV-Vis Spectrograms of Al-MCM-41(50)/BG as time proceeded for adsorbing $\mathrm{NH}_{3}$. The ammonia gas concentration was 5 ppmv.

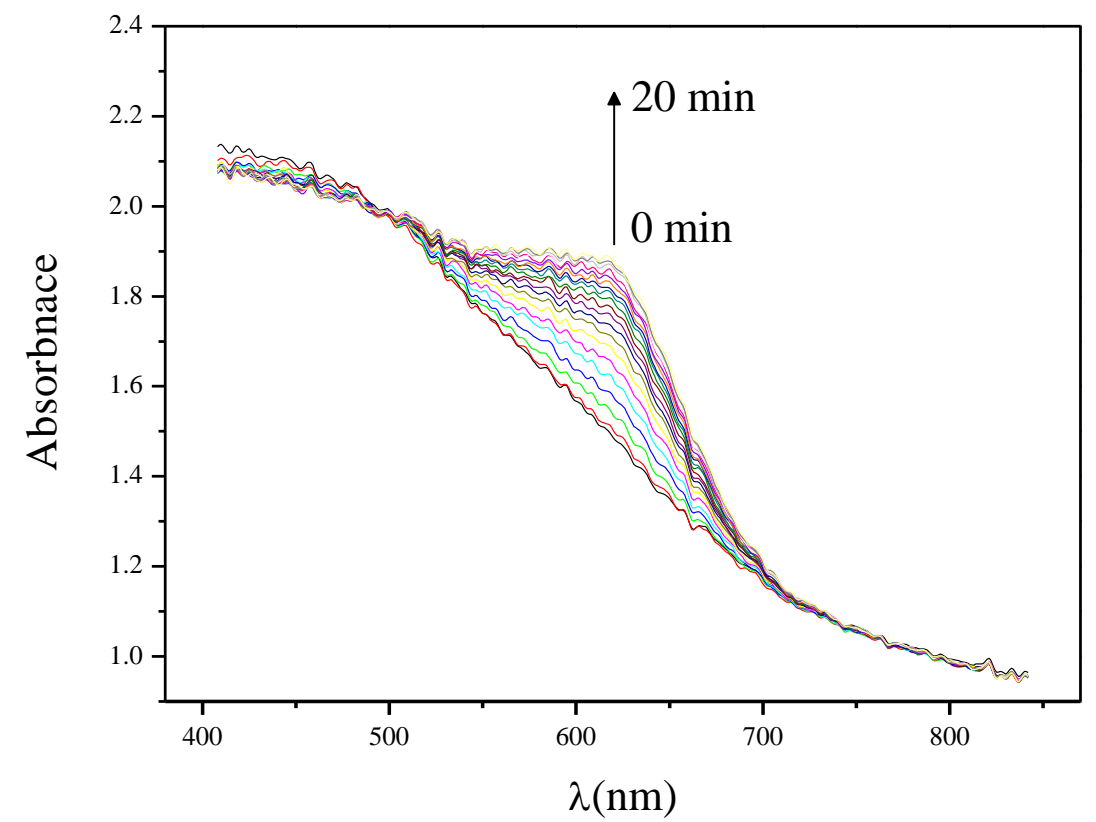

Our goal was to develop an ammonia sensing material capable of quantifying ammonia gas concentrations at sub-ppmv levels. Figure 6 shows the relationship between the absorbance difference and exposure time. The rate of change of the absorbance difference did not increase linearly. The absorbance difference increased quickly after a short $\mathrm{NH}_{3}$ adsorption time (0-20 min), it then increased slowly and gradually reached steady state absorbance. 
When using the dye-impregnated mesoporous material for ammonia sensing, it is not recommended to operate at steady state absorbance conditions. This is because that after long $\mathrm{NH}_{3}$ adsorption times when steady state absorbance is reached, the sensitivity of the dye with respect to different ammonia concentrations tends to decrease, especially when it is oversaturated with ammonia. Besides, the ammonia desorption time may also increase after long ammonia adsorption time. Hence the following cyclic tests were done at an $\mathrm{NH}_{3}$ adsorption time of $20 \mathrm{~min}$.

Figure 6. Time response on the absorbance difference of the Al-MCM-41(50)/BG for monitoring 4.3 ppmv $\mathrm{NH}_{3}$.

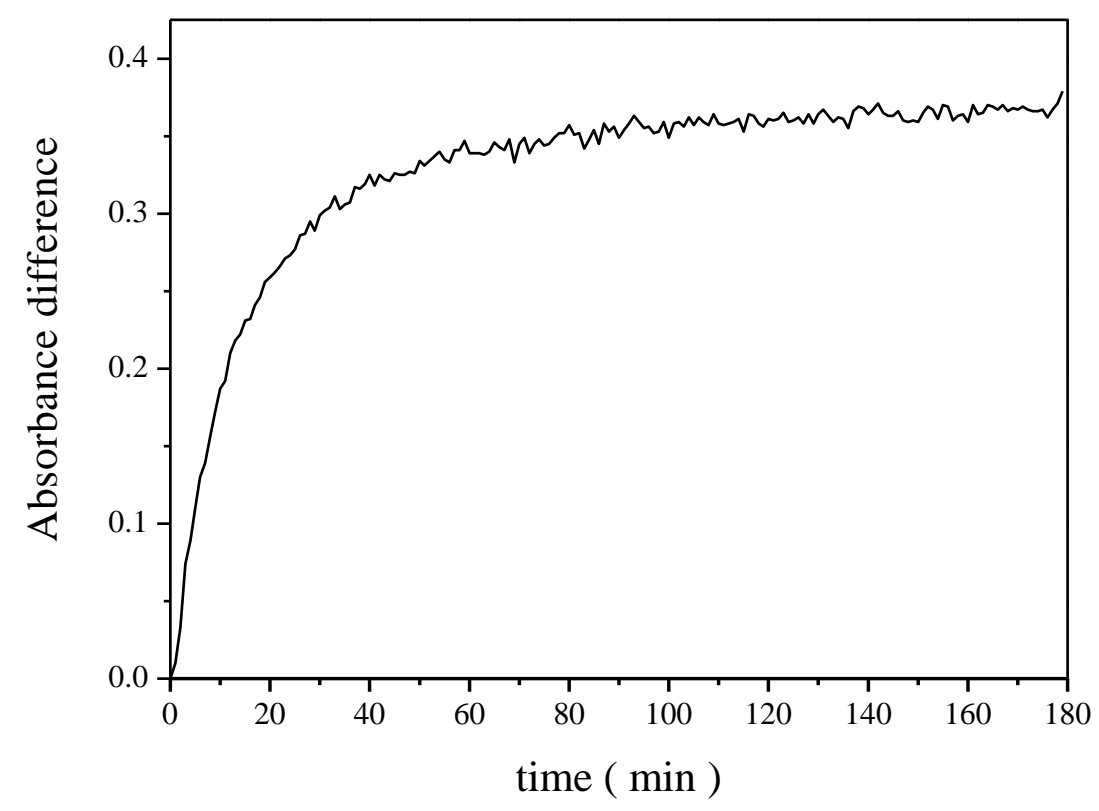

\subsection{Cyclic Test Ability}

The reversibility of the Al-MCM-41(50)/BG material for ammonia sensing was tested for 71 times by repeated adsorption/desorption of ammonia gas using the same testing material at different ammonia concentrations ranging from 0.25 to $4.3 \mathrm{ppmv}$. For the same test ammonia concentration of 1.0 ppmv, tests were performed at the beginning (virgin sample), the 2nd, 45th, 46th, 55th and 56th cycle times. Results on the absorbance difference for the same ammonia inlet concentration of 1.0 ppmv are shown in Figure 7.

It is interesting to observe that the absorbance difference of virgin sample is obviously different from the subsequent test results. This phenomenon occurred for all new tested materials. The reason could be due to that a certain percentage of ammonia gas was chemically adsorbed on the sensing material during the first adsorption cycle and forms a very strong chemical bond which could not be desorbed upon heating at $150{ }^{\circ} \mathrm{C}$. After the first adsorption/desorption cycle of the sensing material, the subsequent ammonia adsorption was only due to physical sorption which could be easily desorbed by heating. Thus the subsequent color change rate became fast and stable. One can see that from the 2nd cycle to the 56th cycle, the average value in the absorbance difference was $0.145 \pm 0.007$ for the five measurement tests, which corresponds to about 5.3\% standard deviation. As a result, it is known that 
the first test result of the virgin sample was not reliable, but after that the material gave stable responses and can be reused for at least tens of cycles.

Figure 7. Reversibility tests of the Al-MCM-41(50)/BG material in the absorbance difference for sensing $1.0 \mathrm{ppmv} \mathrm{NH}_{3}$ after $20 \mathrm{~min}$ of $\mathrm{NH}_{3}$ adsorption.

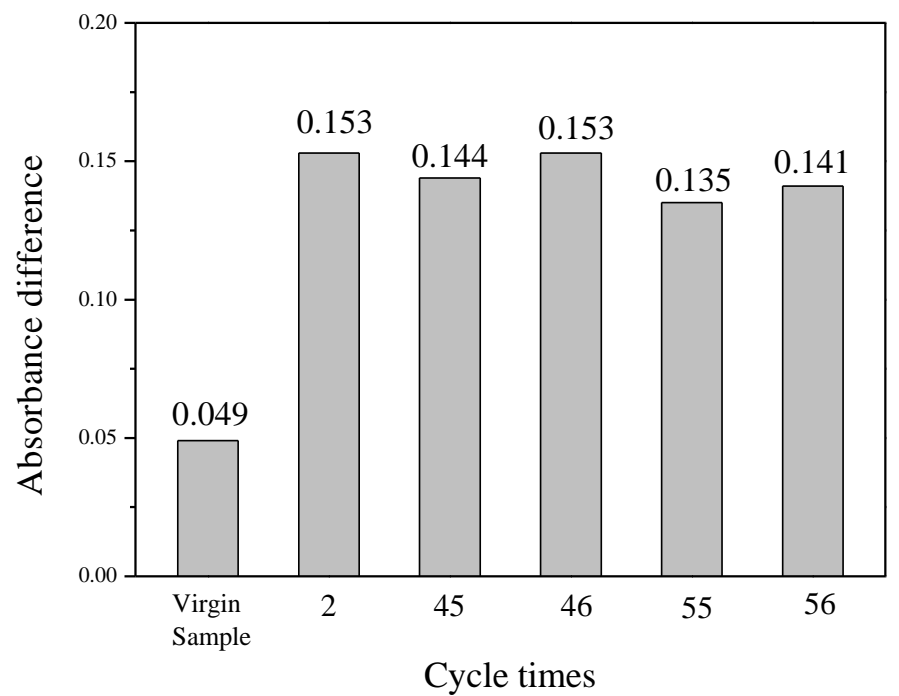

\subsection{Calibration for Sub-ppmv Ammonia Gas}

In order to understand the sensing ability of Al-MCM-41(50)/BG at different sub-ppmv ammonia concentrations, a calibration curve was established and the result is shown in Figure 8 for ammonia testing concentrations of 0.25 to $2.0 \mathrm{ppmv}$.

Figure 8. Calibration curve of the Al-MCM-41(50)/BG for sensing sub-ppmv of $\mathrm{NH}_{3}$ gas concentration. The test time was 5 min for all $\mathrm{NH}_{3}$ concentrations.

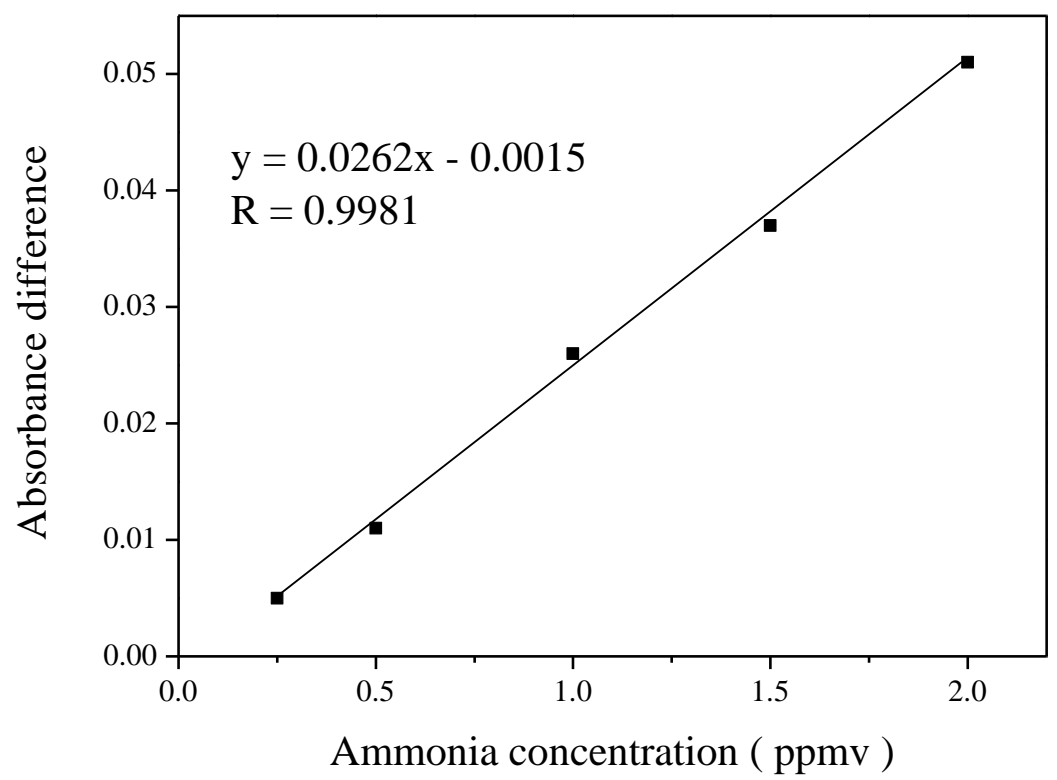

A high linear correlation coefficient $(\mathrm{R}=0.9981)$ was for this test concentration range. By comparing with related research work using silica materials for the same quantification time of $5 \mathrm{~min}$, 
we can see that this material can detect $\mathrm{NH}_{3}$ gas concentrations at least 2 orders lower than those measurable in previous work (145-1,000 ppmv) [23]. In addition to the lower limit of detection, this linear correlation is also better [7,15]. Moreover, the gas quantification time was only 5 min in this study. This means that it has high potential for the industrial application of sensing sub-ppmv ammonia gas concentrations [24]. The method of detection limit (MDL) was calculated by:

$$
\mathrm{MDL}=3 \sigma
$$

where $\sigma$ is the standard deviation of seven repeated measurement data points measured by exposing the sensor to an $\mathrm{NH}_{3}$ gas concentration of $0.75 \mathrm{ppmv}$. The detection limit was found to be $0.185 \mathrm{ppmv}$. As is known from the slope of regression equation shown in Figure 8, the sensitivity of the detection was 0.0262 for sensing $\mathrm{NH}_{3}$ gas in the $0.25 \sim 2.0$ ppmv concentration interval.

\subsection{Effect of the Amount of Material}

The effect of the amount of material on the linear correlation coefficients ( $R$ values) of the calibration curves was evaluated. In the previous results shown in Figure 8, a sample weight of $0.015 \mathrm{~g}$ was used. Here the ammonia sensing ability using a thicker sample of $0.030 \mathrm{~g}$ in weight was also evaluated and compared with that of the thin sample of $0.015 \mathrm{~g}$ in weight. The values of $\mathrm{R}$ for the five point calibration curves between 0.25 and $2 \mathrm{ppmv}$ concentrations were obtained initially for the two sample weights of 0.015 and $0.03 \mathrm{~g}$, respectively. However, the thick $(0.030 \mathrm{~g})$ sample did not have a clear output signal after a short $\mathrm{NH}_{3}$ adsorption time when exposed to 0.25-2 ppmv ammonia concentrations. Hence a higher $\mathrm{NH}_{3}$ concentration range of 1 to $5 \mathrm{ppmv}$ was used for the thick $(0.030 \mathrm{~g})$ sample. The comparison results in terms of $\mathrm{R}$ values at different $\mathrm{NH}_{3}$ adsorption times from 2 to 40 min are shown in Figure 9.

Figure 9. Comparison of the correlation coefficient $(\mathrm{R})$ as a function of $\mathrm{NH}_{3}$ sensing time using different amounts of Al-MCM-41(50)/BG materials.

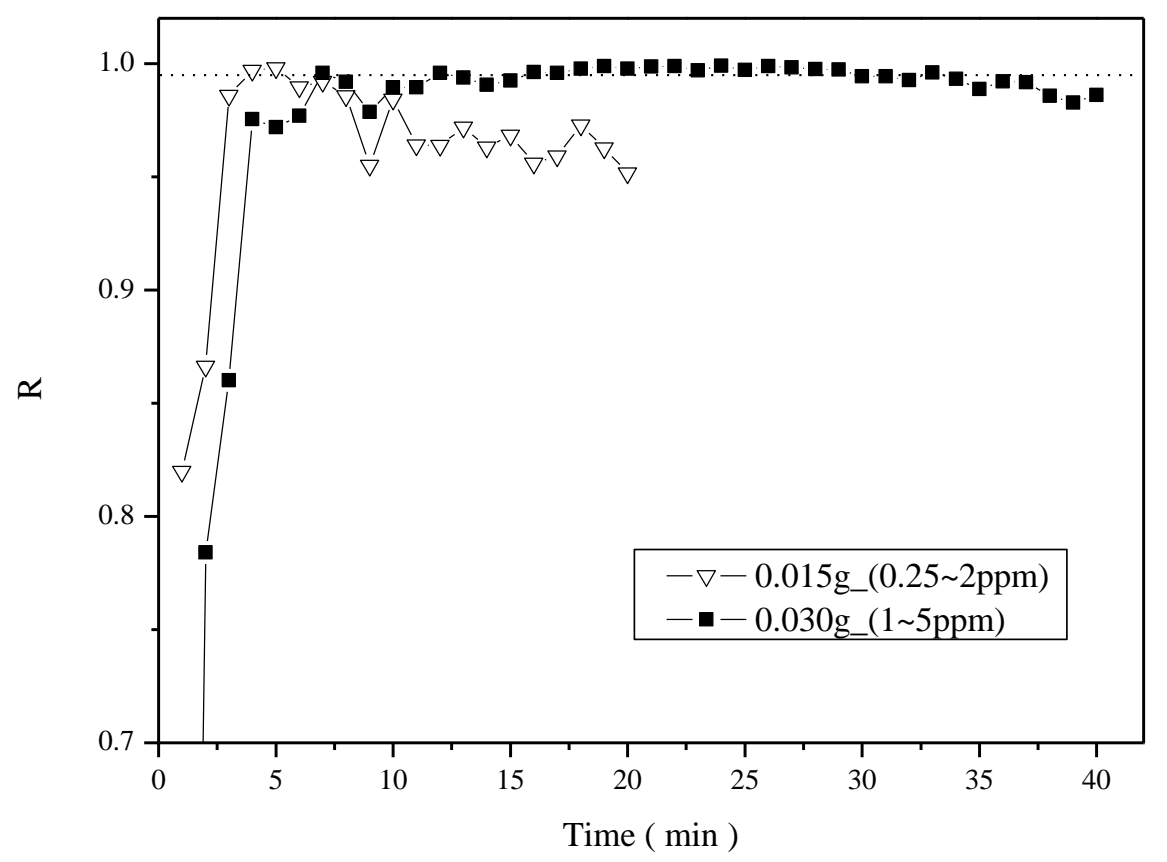


The dotted line shown in Figure 9 represents the $\mathrm{R}$ value of 0.995 , a critical value for indicating a high linear correlation coefficient of the calibration curve. One can see that the required quantitative time with $\mathrm{R}>0.995$ using the light weight sample $(0.015 \mathrm{~g})$ was achieved at a sensing time of only $4 \mathrm{~min}$, which was shorter than that using the heavier weight sample $(0.030 \mathrm{~g}), 8 \mathrm{~min}$. But the time range that $R>0.995$ could be maintained was narrower using the $0.015 \mathrm{~g}$ light weight sample (4-5 min) as compared to the $0.030 \mathrm{~g}$ sample, $12-30 \mathrm{~min}$.

The diffusion effect was considered to be responsible for the results observed in Figure 9. As demonstrated in Figure 10, the thicker the material, the longer the diffusion time would be. Besides, as observed from Figure 9, the correlation coefficient decreased after a few minutes for the case of $0.015 \mathrm{~g}$ sample, which can be explained by the fact that the thin sample was quickly oversaturated with ammonia molecules. Thus the sensitivity of the thin sample decreased quickly and thus the correlation coefficient was decreased. On the other hand, using the $0.03 \mathrm{~g}$ sample which has a thick diffusion layer would result in longer time required for reaching saturated $\mathrm{NH}_{3}$ adsorption. Since the buffered capacity using more amount of sensing material was larger, the high correlation coefficient could be maintained for a longer time using the $0.03 \mathrm{~g}$ sample.

Figure 10. Schematic sketches which show the diffusion effect across the sensing materials of different thickness. (a) thin sample $(0.015 \mathrm{~g})$. (b) thick sample $(0.03 \mathrm{~g})$.

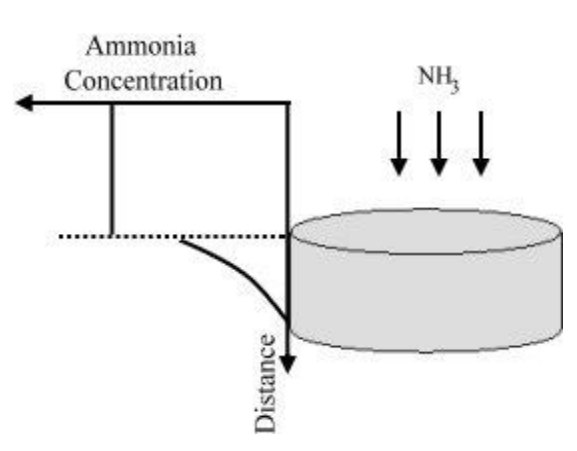

(a)

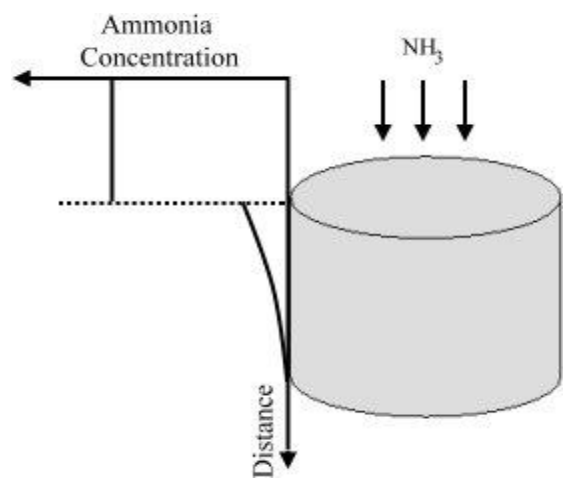

(b)

\section{Conclusions}

An ammonia gas sensing material based on BG dye impregnated on the Al-MCM-41 mesoporous material was proposed. The Al-MCM-41(50)/BG sensing material was orange in color before ammonia gas adsorption, and it changed to blue after exposure to ammonia gas. It was demonstrated by the UV-Vis DRA spectroscopic instrument that the Al-MCM-41(50)/BG is a good sensing material which can detect sub-ppmv ammonia gas concentrations in the range of 0.25 to $2.0 \mathrm{ppmv}$, with a high linear correlation coefficient. In addition, the response time for quantifying the sub-ppmv ammonia gas concentrations was only a few minutes. The color change process was fully reversible during tens of cyclic tests upon repeated adsorption-desorption of the ammonia gas. The only disadvantage of the material is that without heating, the recovery of the sensor material requires $24 \mathrm{~h}$ upon exposure to $\mathrm{N}_{2}$ purge gas, which is not practical for instrumentation. So if the material needs to be recovered for cyclic usage, it would require $1 \mathrm{~h}$ of heating time at $150{ }^{\circ} \mathrm{C}$ which can be engineering designed. The response time and detectable concentration varies with the material weight and thus can be further 
tuned by adjusting the weight of the sensing material for the detection of different ammonia gas concentrations. Such superiority enables the Al-MCM-41(50)/BG to be an attractive mesoporous material for further development and application in the field monitoring of ammonia gas.

\section{Acknowledgements}

The authors would like to thank the Department of Industrial Technology (DoIT), Ministry of Economic Affairs (MOEA) in Taiwan for sponsoring this study.

\section{References}

1. Kanzawa, K.; Kitano, J. A Semiconductor device manufacturer's efforts for controlling and evaluating atmospheric pollution. In Proceedings of 1995 IEEE/SEMI Advanced Semiconductor Manufacturing Conference and Workshop, Cambridge, CA, USA, 13-15 November 1995; pp. 190-193.

2. Ruth, J.H. Odor thresholds and irritation levels of several chemical substances: A review. Am. Ind. Hyg. Assoc. J. 1986, 47, A142-A151.

3. Agency for Toxic Substances \& Disease Registry (ATSDR). Toxicological profile for ammonia, 2004. Available online: http://www.atsdr.cdc.gov/ (accessed on 1 October 2010).

4. The US Occupational Safety and Health Administration (OSHA) website. Available online: http://www.osha.gov (accessed on 1 October 2010).

5. The US National Institute of Occupational Safety and Health (NIOSH) website. Available online: http://www.cdc.gov/niosh (accessed on 1 October 2010).

6. Opdycke, W.N.; Parks, S.J.; Meyerhoff, M.E. Polymer-membrane pH electrodes as internal elements for potentiometric gas-sensing systems. Anal. Chim. Acta 1983, 155, 11-20.

7. Tao, S.; Fanguy, J.C.; Sarma, T.V.S. A Fiber-optic sensor for monitoring trace ammonia in high-temperature gas samples with a $\mathrm{CuCl}_{2}$-doped porous silica optical fiber as a transducer. IEEE Sensors J. 2008, 8, 2000-2007.

8. Markovics, A.; Nagy, G.; Kovacsa, B. Reflection-based sensor for gaseous ammonia. Sens. Actuat. B 2009, 139, 252-257.

9. Courbat, J.; Briand, D.; Damon-Lacoste, J.; Wollenstein, J.; de Rooij, N.F. Evaluation of pH indicator-based colorimetric films for ammonia detection using optical waveguides. Sensors Actuat. B 2009,143, 62-70.

10. Kresge, C.T.; Leonowicz, M.E.; Roth, W.J.; Vartuli, J.C.; Beck, J.S. Ordered mesoporous molecular-sieves synthesized by a liquid-crystal template mechanism. Nature 1992, 359, 710-712.

11. Kosslick, H.; Lischke, G.; Parlitz, B.; Storek, W.; Fricke, R. Acidity and active sites of Al-MCM-41. Appl. Catal. A: Gen. 1999, 184, 49-60.

12. Matsumoto, A.; Chen, H.; Tsutsumi, K.; Grun, M.; Unger, K. Novel route in the synthesis of MCM-41 containing framework aluminum and its characterization. Microporous. Mesoporous. Mat. 1999, 32, 55-62.

13. Fiorilli, S.; Onida, B.; Macquarrie, D.; Garrone, E. Mesoporous SBA-15 silica impregnated with Reichardt's dye: a material optically responding to $\mathrm{NH}_{3}$. Sens. Actuat. B 2004, 100, 103-106. 
14. Onida, B.; Fiorilli, S.; Borello, L.; Viscardi, G.; Macquarrie, D.; Garrone, E. Mechanism of the optical response of mesoporous silica impregnated with Reichardt's dye to $\mathrm{NH}_{3}$ and other gases. $J$. Phys. Chem. B 2004, 108, 16617-16620.

15. Tao, S.; Xu, L.; Fanguy, J.C. Optical fiber ammonia sensing probes using reagent immobilized porous silica coating as transducers. Sens. Actuat. B 2006, 115, 158-163.

16. Karthik, M.; Lin, L.Y.; Bai, H. Bifunctional mesoporous Cu-Al-MCM-41 materials for the simultaneous catalytic abatement of NOx and VOCs. Microporous. Mesoporous. Mat. 2009, 117, 153-160.

17. Ibarra, J.C.; Ortiz-Gutierrez, M.; Alonso-Magana, P. Characterization of bromocresol green and resin as holographic film. Opt. Materials 2004, 27, 567-572.

18. Hung, C.; Bai, H.; Karthik, M. Ordered mesoporous silica particles and Si-MCM-41 for the adsorption of acetone: A comparative study. Sep. Purif. Technol. 2009, 64, 265-272.

19. Zhao, X.S.; Lu, G.Q.; Millar, G.J. Synthesis and characterization of highly ordered MCM-41 in an alkali-free system and its catalytic activity. Catal. Lett. 1996, 38, 33-37.

20. Beck, J.S.; Vartuli, J.C.; Kennedy, G.J.; Kresge, C.T.; Roth, W.J.; Schramm, S.E. Molecular or supramolecular templating: Defining the role of surfactant chemistry in the formation of microporous and mesoporous molecular sieves. Chem. Mat. 1994, 6, 1816-1821.

21. Oberg, K.I.; Hodyss, R.; Beauchamp, J.L. Simple optical sensor for amine vapors based on dyed silica microspheres. Sens. Actuat. B 2006, 115, 79-85.

22. Wang, E.; Sun, Z.S. Ion transfer of bromocresol green across liquid-liquid interfaces. Anal. Chem. 1987, 59, 1414-1417.

23. Cao, W.; Duan, Y. Optical fiber-based evanescent ammonia sensor. Sens. Actuat. B 2005, 110, 252-259.

24. Nakano, N.; Sugata, K.; Nagashima, K. Development of a monitoring tape for ammonia gas in air by fluorescence detection. Anal. Chim. Acta 1995, 302, 201-205.

(C) 2011 by the authors; licensee MDPI, Basel, Switzerland. This article is an open access article distributed under the terms and conditions of the Creative Commons Attribution license (http://creativecommons.org/licenses/by/3.0/). 